\title{
Effects of forest fragmentation on the seedling recruitment of a tropical herb: assessing seed vs. safe-site limitation
}

\author{
María Uriarte, ${ }^{1,5}$ Emilio M. Bruna,, 2 Paulo Rubim, ${ }^{3}$ Marina Anciães, ${ }^{3}$ and Inge Jonckheere ${ }^{4}$ \\ ${ }^{1}$ Department of Ecology, Evolution and Environmental Biology, Columbia University, 1200 Amsterdam Avenue, \\ New York, New York 10027 USA \\ ${ }^{2}$ Department of Wildlife Ecology and Conservation and Center for Latin American Studies, University of Florida, \\ Gainesville, Florida 32611-0430 USA \\ ${ }^{3}$ Biological Dynamics of Forest Fragments Project, Instituto Nacional de Pesquisas da Amazonia and Smithsonian Tropical Research \\ Institute, C.P. 478, Manaus, AM 69011-970 Brazil \\ ${ }^{4}$ Biosystems Department, Geomatics Group, Katholieke Universiteit Leuven, 3001 Leuven, Belgium
}

\begin{abstract}
Studies simultaneously evaluating the importance of safe-site and seed limitation for plant establishment are rare, particularly in human-modified landscapes. We used spatially explicit neighborhood models together with data from 100.5 -ha mapped census plots in a fragmented landscape spanning $1000 \mathrm{~km}^{2}$ to (1) evaluate the relative importance of seed production, dispersal, and safe-site limitation for the recruitment of the understory herb Heliconia acuminata; and (2) determine how these processes differ between fragments and continuous forests. Our analyses demonstrated a large degree of variation in seed production, dispersal, and establishment among and within the 10 study plots. Seed production limitation was strong but only at small spatial scales. Average dispersal distance was less than $4 \mathrm{~m}$, leading to severe dispersal limitation at most sites. Overall, safe-site limitation was the most important constraint on seedling establishment. Fragmentation led to a more heterogeneous light environment with negative consequences for seedling establishment but had little effect on seed production or dispersal. These results suggest that the effects of fragmentation on abiotic processes may be more important than the disruption of biotic interactions in driving biodiversity loss in tropical forests, at least for some functional groups. These effects may be common when the matrix surrounding fragments contains enough tree cover to enable movement of dispersers and pollinators.
\end{abstract}

Key words: Amazonian forest; Heliconia acuminata; landscape modification; safe-site limitation; seed limitation; seedling recruitment.

\section{INTRODUCTION}

Seedling recruitment is a critical bottleneck in the population dynamics of many plant species (Horvitz and Schemske 1994, Wenny 2000). Theoretical and empirical studies also suggest that patterns of seedling establishment can have major consequences for the structure and composition of plant communities (Wright 2002, Levine and Murrell 2003). While the importance for seedling establishment of factors ranging from seed predation to gap dynamics are often studied independently (e.g., Clark and Clark 1989), we still know little regarding the relative importance of individual factors for the establishment of seedlings in most ecological communities.

Successful seedling establishment is generally thought to be limited by either low seed abundance or a limited number of microsites in which seeds can safely germinate, become established, and grow (i.e., seed

Manuscript received 4 May 2009; revised 28 July 2009; accepted 15 September 2009. Corresponding Editor: K. D. Woods.

${ }^{5}$ E-mail: mu2126@columbia.edu limitation and safe-site limitation, respectively; reviewed in Turnbull et al. 2000). Low seed abundance can result from either limited production or the limited dispersal of available seeds, while the factors defining safe sites can be both biotic (e.g., competitors, seed predators) or abiotic (e.g., light levels, soil chemistry). If populations are safe-site limited, then increased seed availability will not result in elevated seedling establishment; additional seeds will simply be arriving in sites where they are unlikely to germinate or thrive. Although the extent to which seedling recruitment is seed- or safe-site-limited remains controversial (Crawley 1990), there is an increasing awareness that their relative importance varies spatially and temporally (Turnbull et al. 2000). Nevertheless, studies simultaneously assessing their relative importance remain rare.

Deforestation in the tropics is continuing at rates that lack historical precedent (Hansen et al. 2008), resulting in the extensive fragmentation of species-rich rain forests (Bierregaard et al. 2002). One of the most common consequences of fragmentation is reduced seedling recruitment, particularly for shade-tolerant or forest understory species (e.g., Benitez-Malvido et al. 1999, Bruna 2002, Melo et al. 2007). Because fruit production 
and disperser abundance are often lower in fragments, these reductions in seedling density have often been attributed to seed limitation (Cardoso da Silva and Tabarelli 2000, Bruna 2002). However, biotic and abiotic changes that follow fragment isolation could also affect the number of available safe sites. For instance, in some locations fragmentation may lead to more seed predators (Burkey 1993), generalist herbivores (Terborgh et al. 2001), and intense competition due to an influx of pioneer tree taxa (Sizer and Tanner 1999). Finally, fragments often have higher air temperatures, reduced relative humidity, and elevated levels of photosynthetically active radiation (Kapos et al. 1997; E. M. Bruna, unpublished data), all of which can inhibit germination or result in seed and seedling mortality.

Processes influencing seedling recruitment are often spatially heterogeneous, which could have important consequences for patterns of safe-site and seed limitation. For instance, the density and distribution of reproductive plants is rarely homogeneous, which can affect pollinator behavior and therefore spatial patterns of fruit abundance (e.g., Feinsinger et al. 1986, 1991). Most seed dispersal is also highly localized: although some seeds can be dispersed long distances, estimated mean dispersal distances are frequently less than $20 \mathrm{~m}$ (Horvitz and Schemske 1994, Clark et al. 1999). The spatial distribution of seed predators is also influenced by the distribution of seed sources, which alters postdispersal patterns of seed abundance (Schnurr et al. 2004). Finally, plants are sessile organisms that engage in competition for resources with nearest neighbors, which are themselves spatially variable in their size and abundance. Despite an increasing appreciation of how neighborhood effects influence population and community dynamics, the application of spatially explicit approaches to elucidate patterns of safe-site and seed limitation remains virtually unexplored (but see MullerLandau et al. 2002).

Safe-site and seed limitation are often evaluated with experimental seed additions and by manipulating environmental factors presumed to influence seed germination (e.g., litter abundance; Bruna 1999). However, seed addition experiments that comprehensively test for seed limitation can be very labor intensive, and many environmental factors that influence seedling establishment are difficult to manipulate in the field (e.g., relative humidity, temperature). An alternative approach that can overcome these shortcomings is spatially explicit neighborhood models (reviewed in Muller-Landau et al. 2002). These models use spatially explicit data on the distribution of potential seed sources, the size and location of competitors, and other biotic or abiotic variables that may affect seedling establishment to parameterize spatially explicit models. The models can then be used to predict seed dispersal and seedling establishment limitation. They have proven particularly useful for systems in which the processes affecting establishment operate at scales that make experimental manipulations prohibitive.

Here we use spatially explicit neighborhood models to elucidate the relative importance of safe-site and seed limitation for recruitment of the Amazonian understory herb Heliconia acuminata and to test competing hypotheses explaining differences in seedling abundance between fragments and continuous forest. Our focal species is the subject of an ongoing demographic study in the Brazilian Amazon (Bruna 2003), and the results of previous work suggest this system is an excellent one with which to investigate mechanisms of safe-site and seed limitation in tropical understory plants. For instance, the abundance of seedlings in a demographic plot is positively correlated with the number of flowering plants that were present during the reproductive season (Bruna 2002), suggesting seed limitation. Evidence for seed limitation also comes from a two-year seed-sowing experiment in which seed additions to both continuous forest and forest fragments always resulted in seedling establishment (Bruna 2002). However, seedling establishment was lower in forest fragments (Bruna 1999, 2002), suggesting changes in fragments influence safesite abundance. We address the following questions: (1) Is seed limitation in $H$. acuminata the result of low seed abundance or limited dispersal, and does the relative importance of these factors vary between forest fragments and continuous forest sites? (2) Are safe sites defined by biotic or abiotic conditions in the locations where seeds are dispersed and seedlings establish, and how does this differ between fragments and continuous forest sites?

\section{Methods}

\section{Study system and site}

All field work was conducted at the Biological Dynamics of Forest Fragments Project (BDFFP) located $70 \mathrm{~km}$ north of Manaus, Brazil $\left(2^{\circ} 30^{\prime} \mathrm{S}, 60^{\circ}\right.$ $\mathrm{W}$; see Plate 1). The BDFFP's $1000-\mathrm{km}^{2}$ landscape is dominated by non-flooded, high-diversity forests (de Oliveira and Mori 1999). In addition to large expanses of continuous forest, the BDFFP has several forest fragment reserves ranging in size from 1 to 100 ha. These fragments were isolated from 1980-1984 by felling of surrounding forests and, in most cases, burning the downed trees once they dried. The regenerating vegetation around the fragments is cleared periodically to insure their continued isolation. The soils in the BDFFP reserves are highly weathered oxisols, which, despite their relatively high clay content, have poor water retention capacity (Laurance et al. 1999). Mean annual temperature is $26^{\circ} \mathrm{C}$ (range $19-39^{\circ} \mathrm{C}$ ), and mean annual rainfall ranges from 1900 to $2300 \mathrm{~mm}$. There is a pronounced dry season from June to December. For a description of the field sites and BDFFP history see Bierregaard et al. (2002).

Heliconia acuminata (Heliconiaceae) is a perennial, understory monocot native to central Amazonia and the 
FIG. 1. The spatial distribution of flowering parents of the understory herb Heliconia acuminata (solid gray circles) and seedling counts in 10 $\times 10$ quadrats (open circles) at the Florestal plot. Size is proportional to the number of inflorescences and seedling counts, respectively. The study was conducted at the Biological Dynamics of Forest Fragments Project (BDFFP) located 70 $\mathrm{km}$ north of Manaus, Brazil.

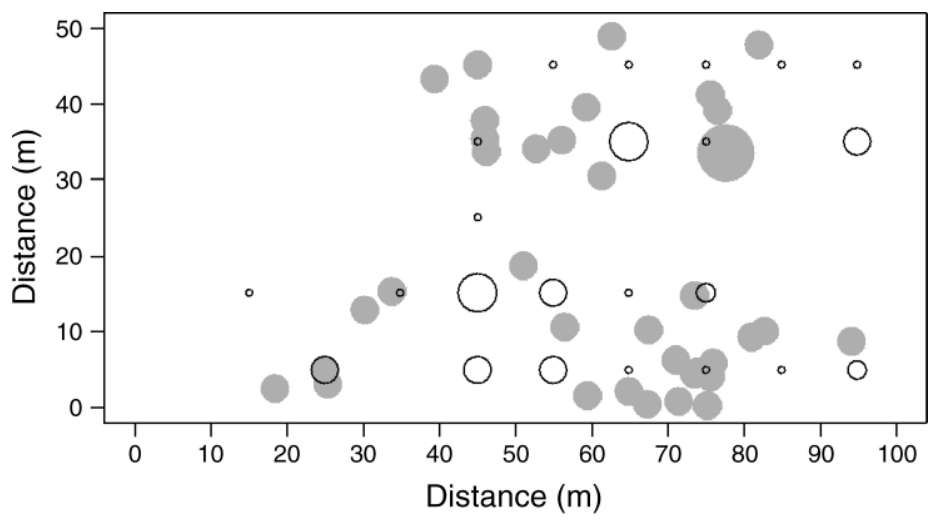

Guyanas (Berry and Kress 1991). In the BDFFP reserves $H$. acuminata flowers and fruits once per year (January-March). Most reproductive plants have one inflorescence with a total of 20-25 flowers; in our study sites $H$. acuminata is pollinated by two hummingbird species: the long-tailed hermit Phaethornis superciliosus and the straight-billed hermit Phaethornis bourcieri (Bruna and Kress 2002). Each flower produces a maximum of three seeds $(1.9 \pm 0.02$ seeds [mean \pm $\mathrm{SE}$, based on dissection of $n=873$ ripe fruits). The seeds germinate 6-7 months later at the onset of the rainy season and rarely beyond then (Bruna 2002). These discrete flowering, fruiting, and germination seasons greatly facilitate surveys for newly established seedlings, and the lack of clonal reproduction (Bruna and Kress 2002) simplifies the interpretation of seedling emergence patterns.

The seeds of all Neotropical Heliconia species are exclusively bird-dispersed (Berry and Kress 1991). In our study sites the primary dispersers are white-necked thrush (Turdus albicollis) and several species of manakin (Pipra erythrocephala, P. pipra, P. serena, Corapipo gutturalis, Schiffornis turdinus; P. Stouffer, personal communication; M. Anciães, unpublished data). These species can be divided into two broad categories based on their fruit-handling techniques. Thrushes are larger birds that perch to swallow fruits and may regurgitate seeds locally or defecate them at longer distances. In contrast, manakins are smaller birds that swallow fruits, immediately move away from the fruiting plant, and regurgitate seeds (Stiles 1979; M. Anciães, personal observation).

In January 1998, a series of permanent demographic plots (each $50 \times 100 \mathrm{~m}$ ) were established in the BDFFP reserves in which all $H$. acuminata were marked with an aluminum tag and measured. All plots were subdivided into $5010 \times 10$ quadrats to facilitate the surveying and mapping of plants (Bruna and Kress 2002). Since their establishment the plots have been censused annually, and all plants have been mapped. The present study is based on data collected in plots located in continuous forest $(N=6)$ and 1-ha fragments $(N=4)$ during the 2006 and 2007 censuses. In 2006 we mapped all established plants to the nearest meter; we also recorded the number of inflorescences produced by each reproductive plant. In 2007, we recorded and mapped all new seedlings (Fig. 1).

\section{Modeling framework}

We used inverse models parameterized with observational data (reviewed in Muller-Landau et al. 2002) to characterize $H$. acuminata seed production, dispersal, and seedling establishment and to evaluate the factors influencing seed and safe-site limitation and how they differ between fragments and continuous forests. This method assumes that observed spatial variation in seedling abundance is a multiplicative function of seed production, which is based on the size of potential seed sources, and local dispersal, which is modeled with a dispersal kernel that adjusts for proximity of the sources to seedling quadrats (e.g., Fig. 1). The density of dispersed seeds can then be modified by biotic and abiotic drivers of establishment.

To estimate seedling recruitment, we calculated the total number of seedlings in the 2007 census in each demographic plot's $5010 \times 10 \mathrm{~m}$ quadrats (Table 1). Although this spatial scale is coarse relative to the size of adult $H$. acuminata plants, the low seedling density $(0.83$ \pm 0.85 seedlings/quadrat) made it necessary to use this quadrat size to obtain robust parameter estimates for our model (Kobe and Vriesendorp 2009).

The total number of seeds, $t$, produced by a reproductive plant during the 2006 flowering season was estimated as a function of its number of inflorescences $(m)$ as follows:

$$
t=\frac{a \times m}{1+(a / b) \times m}
$$

where the parameter $a$ determines the steepness in the increase in seed production with the number of inflorescences and $b$ determines the asymptote of the inflorescence-seed production relationship. Implicit in this functional form is the assumption that the number of seeds per inflorescence will decrease with the total number of inflorescences within an individual plant 
TABle 1. Number of reproductive parents of the understory herb Heliconia acuminata in 2006, seedlings in 2007 in the 10 study plots, and percentage of $10 \times 10$ quadrats within each plot with no seedlings.

\begin{tabular}{llcccc}
\hline \hline Plot name & Size & No. inflorescences in 2006 & No. seedlings in 2007 & Quadrats without seedlings (\%) & GLI \\
\hline 2107 & 1 ha & 10 & 8 & 42 & $0.088(0.034)$ \\
2108 & 1 ha & 30 & 11 & 40 & $0.086(0.056)$ \\
5751 & $1 \mathrm{ha}$ & 27 & 9 & 41 & $0.091(0.026)$ \\
5753 & $1 \mathrm{ha}$ & 6 & 44 & 46 & $0.141(0.117)$ \\
5750 & $\mathrm{CF}$ & 56 & 34 & 29 & $0.049(0.021)$ \\
5756 & $\mathrm{CF}$ & 35 & 18 & 31 & $0.031(0.004)$ \\
Cabo Frio & $\mathrm{CF}$ & 5 & 41 & 43 & $0.096(0.032)$ \\
Dimona & $\mathrm{CF}$ & $\mathrm{CF}$ & 8 & 27 & $0.031(0.013)$ \\
Florestal & $\mathrm{CF}$ & 37 & 43 & $0.071(0.0211)$ \\
Porto Alegre & $\mathrm{CF}$ & 3 & & $0.130(0.057)$ \\
\hline
\end{tabular}

Notes: Mean and SD (in parentheses) values for gap light index (GLI) were calculated from hemispheric photos. The study was conducted at the Biological Dynamics of Forest Fragments Project (BDFFP) located $70 \mathrm{~km}$ north of Manaus, Brazil. CF stands for continuous forest.

because of pollination limitation or limited resource availability.

Heliconia acuminata is bird dispersed, and most seeds are dispersed some distance from the parent plant (M. Anciães, unpublished manuscript). For this reason, we chose a lognormal dispersal function, which is well suited to a variety of dispersal mechanisms, including the passage of seeds by animals (Greene and Johnson 1992). The kernel takes the following form:

$$
f(d)=\frac{1}{\eta} \exp -\frac{1}{2}\left(\frac{\ln \left[d / X_{0}\right]}{X_{\mathrm{b}}}\right)^{2}
$$

where $\mathrm{d}$ is the observed distance between the flowering plan and the seedling quadrat, $\mathrm{X}_{0}$ is the distance at which maximum recruitment occurs (i.e., the mode of the dispersal kernel), $\mathrm{X}_{\mathrm{b}}$ determines the breadth or spread of the dispersal kernel, and $\eta$ is a normalization constant equal to the arcwise integration of the dispersal kernel (Ribbens et al. 1994).

Combining local seed production and the dispersal kernel results in a model for the potential number of seedlings $(R)$ in a $10 \times 10 \mathrm{~m}$ quadrat $i$ over the course of a single reproductive season:

$$
R_{i}=\sum_{k=1}^{n} \frac{a \times m_{k}}{1+(a / b) \times m_{k}} f\left(d_{i k}\right)
$$

where $m_{k}$ is the number of inflorescences of $k=1 \ldots n$ plants within the maximal dispersal distance (in meters) suggested by our model and $d_{i k}$ is the distance from quadrat $i$ to plant $k$, and $f()$ is the appropriate dispersal kernel.

Our previous studies and knowledge of the natural history of this system allow us to exclude several factors that may define safe sites in other systems. For instance, predation of $H$. acuminata seeds in both fragments and continuous forest is very limited (Bruna 1999), as is seedling herbivory by both vertebrates and invertebrates (Bruna 2002). There is also no evidence that fungal pathogens are a major source of $H$. acuminata seedling mortality (E. M. Bruna, personal observation), and community-wide rates of seedling infection in Central
Amazonia are extremely low (Benitez-Malvido et al. 1999). Finally, under identical conditions, seeds from fragments are not less likely to germinate than those from continuous forest (Bruna 1999), suggesting the effects of inbreeding on recruitment are limited. Therefore, we emphasize mechanisms that our previous empirical work suggests are most relevant and that have been shown to strongly influence seedling recruitment in other herbs: canopy cover (a surrogate for the amount of light reaching the forest floor) and the density of established conspecific plants (Flinn and Vellend 2005, Schleuning et al. 2009). To this end, we modified the basic inverse model to account for the following factors.

1. Density-dependent interactions with established $\mathrm{H}$. acuminata.-The density of established ( $>12 \mathrm{~cm}$ height) H. acuminata plants in the $50 \times 100 \mathrm{~m}$ demographic plots varies eightfold (Bruna and Kress 2002), and there is also substantial variation in density at the $10 \times 10 \mathrm{~m}$ scale within census plots (Table 1). There is therefore the potential for seedlings to be competing with previously established plants, most of which are orders of magnitude greater in biomass. We incorporated density-dependent interactions in the model by first calculating the number of established plants in each of the $10 \times$ $10 \mathrm{~m}$ quadrats of each plot and estimating the effects that this increase in conspecific density would have on seedling recruitment. The total number of seedlings $\mathrm{Sd}_{i}$ potentially recruited in quadrat $i$ becomes

$$
\mathrm{Sd}_{i}=\sum_{k=1}^{n} \frac{a \times m_{k}}{1+(a / b) \times m_{k}} f\left(d_{i k}\right)+g \times P_{i}
$$

where $P_{i}$ is the number of adult plants in quadrat $i$ and $g$ is the estimated density dependence parameter. Using this formulation, negative density dependence is straightforward to interpret. However, positive density dependence may be indicative of favorable conditions for establishment or increased pollinator visitation (Feinsinger et al. 1986, 1991), thereby confounding biotic and abiotic drivers of seedling establishment. However, previous research at the site has demonstrated that $H$. acuminata reproductive success is independent of 
local flower density (Bruna et al. 2004). This allows us to interpret positive density dependence with established plants as a proxy for habitat favorability, an approach often used in plant ecology (e.g., Iverson and Prasad 1998). Although a positive or a negative value of $g$ could mask some density dependence of the opposite sign, this approach allows us to identify the predominant effect.

2. Abiotic factor: light levels.-We used hemispherical photography to quantify growing-season light availability in each of the $5010 \times 10 \mathrm{~m}$ quadrats in each study plot. Photographs were taken on a leveled platform at 1 $\mathrm{m}$ from the ground in the center of the quadrat. We used a thresholding algorithm that ensures objective and repeatable results (Jonckheere et al. 2005) to calculate percentage of light transmission as a measure of available light at each quadrat in each plot. Inspection of the data suggested that seedling recruitment increased with light availability up to a point, but fell off abruptly beyond this threshold (Fig. 2A). For this reason, the effect of light availability on $H$. acuminata establishment was calculated as a function of two estimated parameters: $L_{\text {th }}$ determines the light level (transmission, TR) beyond which seedling establishment stops and $L$ determines the slope of the relationship between light availability and seedling recruitment below the threshold. The effect of light transmission on quadrat $i$ becomes

$$
f\left(\mathrm{TR}_{i}\right)= \begin{cases}L \times \mathrm{TR}_{i} & \text { if } \mathrm{TR}_{i}<L_{\mathrm{th}} \\ 0 & \text { if } \mathrm{TR}_{i} \geq L_{\mathrm{th}}\end{cases}
$$

Combining Eqs. 4 and 5, the total number of seedlings $S_{i}$ expected to establish at quadrat $i$ is

$$
S_{i}=\mathrm{Sd}_{i} f\left(\mathrm{TR}_{i}\right) .
$$

\section{Model comparison}

To assess the importance of each individual process on seedling recruitment and how their relative importance varied between fragments and continuous forests, we compared alternative candidate models using Akaike information criterion (AIC; Burnham and Anderson 2002). These models described the basic mechanisms and potential effects of fragmentation on seed production, seed dispersal, and seedling establishment. For instance, to determine the importance of dispersal we compared a model that incorporated a dispersal kernel (Eq. 2) with a null model that assumed that seeds were evenly distributed across quadrats. We examined the importance of individual biotic and abiotic factors on recruitment by comparing a basic set of models that include all potential combinations of the biotic and abiotic processes we considered.

To quantify the effects of fragmentation on seed production, dispersal, and establishment, we included models that assumed that each of these processes can vary between fragments and continuous forests. For instance, fragmentation could affect the effectiveness of
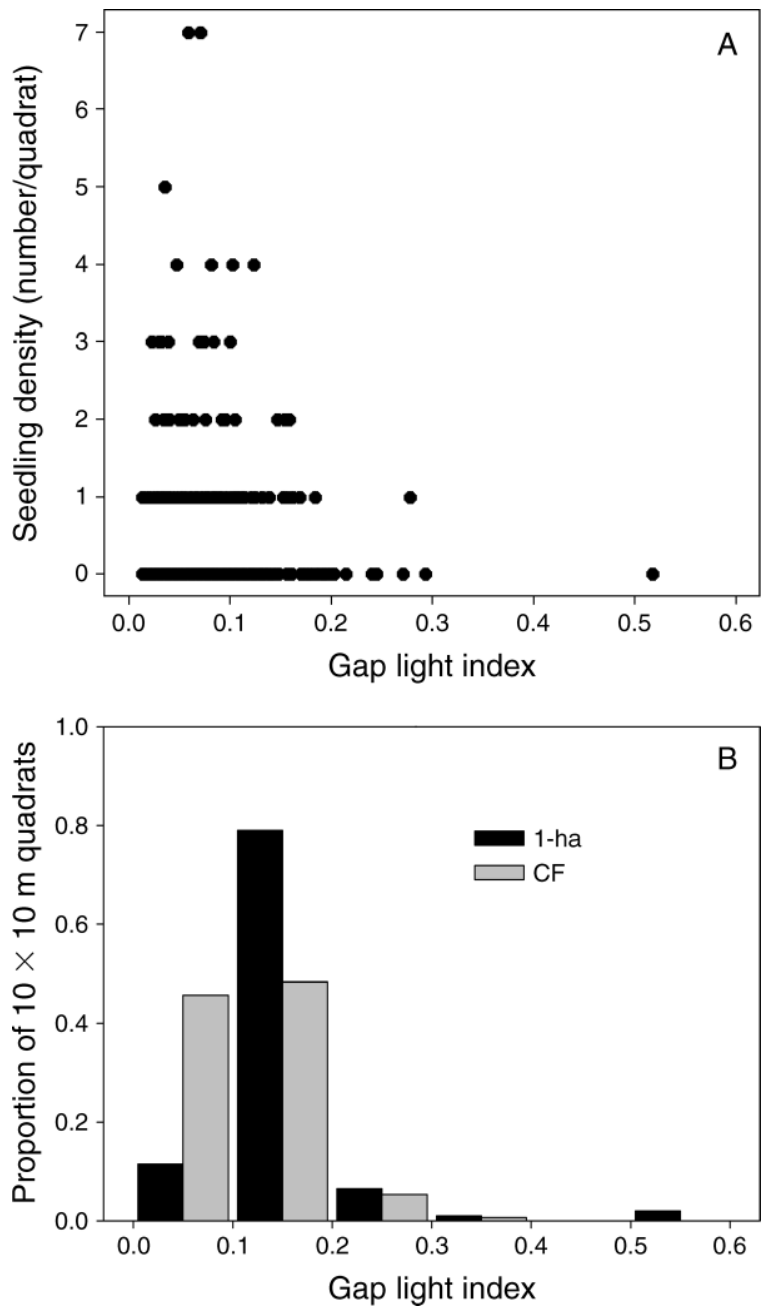

FIG. 2. (A) Light availability (gap light index, GLI; higher values are associated with greater light availability) and seedling densities per quadrat in our study plots. (B) Distribution of light in $10 \times 10 \mathrm{~m}$ quadrats in 1-ha $(n=200)$ and continuous forest $(\mathrm{CF} ; n=300)$ plots.

pollinators (parameters $a$ and/or $b$ in Eq. 1), disperser movement and the shape of the dispersal kernel (parameter $X_{0}$ in Eq. 2), or the effect that light availability has on establishment (parameter $L$ or $L_{\mathrm{th}}$ in Eq. 5).

For all analyses we assumed that the expected density of recruits in a quadrat follows a negative binomial distribution, reflecting the high degree of clumping observed in the data (Clark et al. 1998). We used simulated annealing, a global optimization algorithm, to find the parameter values that maximized the likelihood of observed recruitment densities. We also calculated asymptotic $95 \%$ support limits for all the parameters. For the goodness-of-fit calculations, seedling densities were $\log$ transformed as $\log ($ seedlings +1$)$ to reduce deviation from normality (Zar 1996). A list of estimated parameters is provided in Table 2. 
TABLE 2. Definitions of estimated model parameters.

\begin{tabular}{|c|c|}
\hline Parameter & Description \\
\hline$a$ & $\begin{array}{l}\text { linear effect of number of inflorescences on seed } \\
\text { production }\end{array}$ \\
\hline$b$ & $\begin{array}{l}\text { asymptote of the relationship between number } \\
\text { of inflorescences and seed production }\end{array}$ \\
\hline$X_{0}$ & mode of the dispersal kernel \\
\hline$X_{\mathrm{b}}$ & variance of the dispersal kernel \\
\hline$g$ & effect of adult density on recruitment \\
\hline$L$ & effect of light transmission on seedling establishment \\
\hline$L_{\mathrm{th}}$ & $\begin{array}{l}\text { maximum light transmission threshold for } \\
\text { seedling establishment }\end{array}$ \\
\hline
\end{tabular}

\section{Assessing seed and safe-site limitation}

To estimate potential seed production limitation, we used data on the number of inflorescences for reproductive plants in each plot together with a mean of 20 fruits with three seeds per fruit produced per inflorescence. This is a conservative estimate with respect to tests of seed production limitation because this number is the maximum observed seed production and we assume no seed predation (Bruna and Kress 2002). Seed production limitation at each study plot was calculated as the proportion of $10 \times 10$ quadrats at which no seeds arrived, estimated stochastically as a Poisson seed rain with equal expectation across all quadrats. The proportion of quadrats $(n)$ at which none of the seeds produced in the plot $(s)$ arrive is

$$
\text { source limitation }=\exp (-s / n) \text {. }
$$

We then used seed production numbers and our estimated dispersal kernels to determine dispersal limitation at the quadrat level as the proportion of 10 $\times 10 \mathrm{~m}$ quadrats in each plot that failed to receive seeds. Finally, the difference between dispersal limitation and patterns of established seedlings provided an index of safe-site limitation, calculated as $1-r / a$, where $r$ is the number of quadrats with established seedlings and $a$ is the proportion of quadrats that would receive seeds according to our estimates of seed production and dispersal (see Clark et al. 1998). Finally, to assess the effects of fragmentation on seedling recruitment processes, we compared the values of all limitation metrics between fragments and continuous forests. All analyses were conducted using $\mathrm{R}$ statistical software ( $\mathrm{R}$ Development Core Team 2008).

\section{RESUlts}

Our analyses demonstrated both seed and safe-site limitation of $H$. acuminata recruitment at the study site, with large variation in the magnitude of the processes that determine seed production, dispersal, and establishment among and within the 10 study plots (Tables 1 and 3). The most parsimonious model, which included dispersal, positive density-dependent interactions with established plants, and a positive effect of light on seedling establishment below a threshold value (Appendix A), produced a moderate fit to the data $\left(R^{2}=0.23\right)$, a result we expected in light of the complex behavior of animal dispersers in heterogeneous landscapes (Russo et al. 2006). Results highlighted the importance of light and habitat favorability (as reflected by density of established plants) as the primary factors limiting recruitment of $H$. acuminata in these forests.

\section{Seed limitation}

Assuming that each inflorescence produces 20 fruits with three seeds per fruit (Bruna and Kress 2002) and no dispersal or safe-site limitation, we found virtually no seed production limitation across the study plots at a scale of $10 \times 10 \mathrm{~m}$ (Table 3). However, these numbers change drastically if we evaluate seed production limitation at a finer spatial grain (Kobe and Vriesendorp 2009). For instance, at $1 \times 1 \mathrm{~m}$ scales there would not be enough seeds to reach $0.01-78 \%$ of the quadrats at the study plots.

The AIC values indicated that a model that includes dispersal was a better fit to the data than a null model that assumes seeds are evenly distributed between

TABLE 3. Estimated limitation in seed production and dispersal and seedling establishment of the understory herb Heliconia acuminata in the study plots.

\begin{tabular}{lccccc}
\hline \hline Site & $\begin{array}{c}\text { No. } \\
\text { inflorescences }\end{array}$ & $\begin{array}{c}\text { Estimated } \\
\text { seed production }\end{array}$ & $\begin{array}{c}\text { Production } \\
\text { limitation }\end{array}$ & $\begin{array}{c}\text { Dispersal } \\
\text { limitation }\end{array}$ & $\begin{array}{c}\text { Establishment } \\
\text { limitation }\end{array}$ \\
\hline 2107 & 10 & 600 & $<0.000001$ & 0.42 & 0.72 \\
2108 & 30 & 1800 & $<0.000001$ & 0.30 & 0.71 \\
5751 & 27 & 1620 & $<0.000001$ & 0.02 & 0.82 \\
5753 & 6 & 360 & $<0.00075$ & 0.54 & 0.83 \\
5750 & 56 & 3360 & 0.000001 & 0.00 & 0.58 \\
5756 & 5 & 300 & 0.09 & 0.02 & 0.61 \\
Cabo Frio & 2 & 120 & 0.09 & 0.64 & 0.62 \\
Dimona & 2 & 2220 & $<0.000001$ & 0.16 & 0.45 \\
Florestal & 37 & 180 & $<0.000001$ & 0.68 & 0.56 \\
Porto Alegre & 3 & & & & \\
\end{tabular}

Notes: Total seed production was calculated by assuming that each inflorescence produces 20 flowers each with three seeds (Bruna and Kress 2002) and all seeds are distributed evenly among quadrats. Dispersal limitation was calculated by simulating dispersal of produced seeds using estimated parameters for Eq. 2 and calculating the percentage of quadrats that received no seeds. Seedling establishment limitation was calculated as the proportion of quadrats to which seeds are estimated to disperse but where seedlings fail to establish. See Methods: Assessing seed and safe-site limitations for more details. 
TABLE 4. Maximum-likelihood parameter estimates (MLE) and support intervals (SI) for the most parsimonious model.

\begin{tabular}{|c|c|c|c|}
\hline Parameters & MLE & Lower SI & Upper SI \\
\hline$a$ & 0.67 & 0.41 & 1.00 \\
\hline$b$ & 4.60 & 1.00 & 10.00 \\
\hline$L_{\text {frag }}$ & 4.10 & 3.36 & 11.62 \\
\hline$L_{\mathrm{CF}}$ & 21.48 & 20.19 & 45.04 \\
\hline Conspecific density dependence $(g)$ & 0.03 & 0.03 & 0.04 \\
\hline$X_{0}$ & 3.64 & 2.22 & 4.18 \\
\hline$X_{b}$ & 0.82 & 0.66 & 0.86 \\
\hline$L_{\mathrm{th}}$ & 0.33 & 0.28 & 0.40 \\
\hline
\end{tabular}

Notes: Key to parameters: $\mathrm{L}_{\text {frag }}$, effect of light transmission on seedling establishment in fragments; $L_{\mathrm{CF}}$, effect of light transmission on seedling establishment in continuous forest. See Table 2 for explanations of other parameter abbreviations.

quadrats (Appendix A). Moreover, our inverse modeling results suggest that most seeds are dispersed short distances from reproductive plants, which is consistent with the potential importance of dispersal limitation (Table 4). Since collection of dispersed seeds is not feasible in our study system, we could not evaluate the degree of dispersal limitation at the sites directly. However, we used parameter values from our estimated dispersal kernel together with data on the location and reproductive effort (number of inflorescences) of reproductive plants to estimate seed dispersal limitation at the study sites (see Methods: Assessing seed and safe-site limitation). Results from these simulations show severe dispersal limitation at a $10 \times 10 \mathrm{~m}$ scale (Table 3 ). We also demonstrated large variation between and within plots in the magnitude of dispersal limitation with the percentage of quadrats that did not receive any seeds ranging from $0 \%$ in plot 5750 to $68 \%$ in plot PA-CF.

We examined the effects of fragmentation on seed limitation using two complementary approaches. First, we determined whether seed production or seed dispersal limitation differed between fragments and continuous forests (Table 3 ). Second, we varied parameters $a$ and $b$ in Eq. 1 and parameter $X_{0}$ in Eq. 2 to assess whether fragmentation influences either seed production or the mode of the dispersal kernels and hence the degree of dispersal limitation. Results from these two approaches provided consistent answers. First, model comparison showed that the data do not support a difference in the shape of the relationship between inflorescence number and seed production or in dispersal kernels between fragments and continuous forests (Appendix B). Second, we found no differences in seed production limitation $(t$ $=0.066, P=0.47)$ or seed dispersal limitation $(t=-0.09$, $P=0.46)$ between 0.5 -ha plots in forest fragments and continuous forests, although both seed production and seed dispersal limitation were far more variable within and between plots in continuous forests than in fragments (Table 3 ).

\section{Safe-site limitation}

We considered abiotic and biotic factors that can influence seedling recruitment in $H$. acuminata. The former included the potential effects of light while the latter accounted for density-dependent interactions with conspecifics. Of these factors, models were most improved by inclusion of positive density dependence with established plants (Appendix A). A higher number of established plants in the plot, regardless of their reproductive status, was associated with greater seedling recruitment. The most parsimonious model also included effects of light. We found a threshold light transmission beyond which seedling establishment fails, as well as a linear positive relationship between light availability and seedling recruitment below the threshold (Figs. 2A and 3).

We also examined whether fragmentation affected the importance of the factors determining safe-site limitation in our system. Mean light levels were higher in fragments than in continuous forests ( $t$ test on logtransformed light transmission data, $t=8.7013$, df $=$ 478.351, $P<2.2 \times 10^{-16}$; Fig. 2B). The most parsimonious model included differences between continuous forests and fragments in the effects of light availability on seedling recruitment. Parameter $L$ in Eq. 5 , which determines the magnitude of the effect of light on recruitment, increased fivefold from fragments to continuous forests (Fig. 3). We failed to detect any effects of fragmentation on light threshold levels or on density-dependent interactions with conspecifics (Appendix B).

Given that seedling establishment rates and our calculations of seed dispersal were based on data collected at the same spatiotemporal scales, we could also calculate safe-site limitation at each of our 10 study plots (Table 3). These calculations demonstrate that seedling establishment limitation is stronger in fragments than in continuous forests (mean $=0.77$ in fragments vs. 0.53 in $\mathrm{CF}, t=5.01, P=0.0002$ ), which

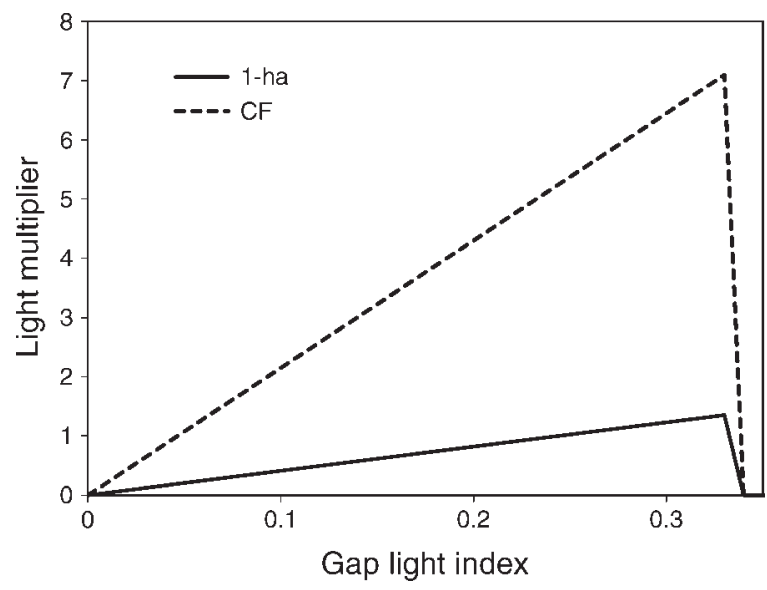

FIG. 3. The relationship between light availability (gap light index, GLI) and light multiplier, parameter $L$, the effect of light transmission on seedling establishment. We assumed a linear increase in seedling establishment with light up to a threshold level beyond which establishment did not occur. See Table 3 for parameter values. 
is consistent with the hypothesis that the seed germination or seedling establishment environment is less favorable in fragments.

\section{Discussion}

Studies simultaneously evaluating safe-site and seed limitation of seedling establishment are rare (but see Flinn 2007, Jacquemyn and Brys 2008), particularly in tropical systems. Furthermore, most studies investigating recruitment in the tropics have focused on trees (e.g., Muller-Landau et al. 2002), despite the fact that herbs and other understory plants can represent up to $25 \%$ of the diversity in tropical forests (Gentry and Emmons 1987). Our results suggest that the effects of fragmentation on the recruitment of herbaceous species are more complex than previously suggested (Cardoso da Silva and Tabarelli 2000, Bruna 2003) and that they extend beyond a simple safe-site vs. seed limitation dichotomy.

\section{Effects of inflorescence abundance and potential dispersal on seed limitation}

Seed limitation is strong for many plant species (Flinn and Vellend 2005, Svenning and Wright 2005). In our system the number of inflorescences, and therefore number of potential seeds produced, varied 20-fold across the study plots (Table 1). Although seed production limitation at the scale of a $10 \times 10 \mathrm{~m}$ quadrat, that is, the percentage of quadrats that did not produce at least one seed, was similar among study areas, these rates varied from $0.1 \%$ to $78 \%$ among sites at a scale of $1 \times 1 \mathrm{~m}$, indicating that seed input limitation at the scale occupied by a reproductive adult plant can be extremely high (Table 3; Kobe and Vriesendorp 2009). This result is not surprising since forests in Central Amazonia have among the lowest recorded levels of plant fertility in the tropics (Gentry and Emmons 1987).

Although previous work suggested there was a large influx of seeds from continuous forest into nearby forest fragments (Bruna 2003), our results suggest this is not the case: the mean estimated dispersal distance for $H$. acuminata was $<4 \mathrm{~m}$ (Table 4 , Fig. 1), resulting in strong dispersal limitation across and within sites (range 2-68\%). Previous efforts to describe the dispersal kernel of vertebrate dispersed seeds have focused primarily on measuring movement patterns and seed passage rates of frugivores (e.g., Westcott and Graham 2000), and there has been some criticism in the literature of seed dispersal kernels derived from seedling quadrat or seed trap data (e.g., Holbrook and Loiselle 2007). However, the short mean dispersal distances we estimated for $H$. acuminata are consistent with those of other understory herbs (Cain et al. 1998, Svenning and Skov 2002) and the foraging behavior of $H$. acuminata's dispersers. Many frugivores cache food, have nest sites to which they return after foraging (e.g., Russo et al. 2006), or swallow and digest seeds for relatively long periods (e.g., Westcott and Graham 2000). Manakins, however, rarely swallow seeds but rather regurgitate them after a few minutes while perching on nearby trees (Stiles 1979). Radio telemetry data and foraging experiments conducted at the study site further support our conclusion that short-distance dispersal is prevalent in H. acuminata (M. Uriarte, M. Anciães, and E. M. Bruna, unpublished data). This pattern has also been observed for other Heliconia species, possibly resulting from their large seed sizes relative to bird gut size (Stiles 1979, Schleuning et al. 2009). We are therefore confident that the estimated dispersal kernels accurately reflect dispersal limitation for $H$. acuminata.

\section{Effects of fragmentation on seed production and dispersal limitation}

Our results showed that the relationship between inflorescence number and seed production (Eq. 1) did not vary between fragments and continuous forest. This suggests that pollination rates were relatively unaffected by fragmentation, perhaps because hummingbirds appear to readily move through the secondary growth surrounding fragments (Antongiovanni and Metzger 2005, Stouffer et al. 2006). However, the effects of fragmentation on seed production are likely to differ with mating systems and pollinator behavior (Aizen and Feinsinger 1994). By altering plant resources (e.g., water, light, nutrients), fragmentation may also affect maternal resource limitation, which could lead to differential seed production between fragments and continuous forests without any pollination decline (e.g., Aizen and Feinsinger 1994). Although we did not explicitly test for effects of the abiotic environment on seed production, model comparison failed to support consistent differences in seed production between fragments and continuous forests, and previous observations suggest per capita seed production is similar in these two habitat types (Bruna and Kress 2002). However, seed production was far more variable within and between plots in continuous forests than in fragments with very high seed production in some of the continuous forest plots (Table 1). These large populations probably indicate habitat suitability (e.g., edaphic control) at some but not all of the continuous forest sites.

The magnitudes of seed dispersal limitation were comparable for fragments and continuous forests (Table 3). Moreover, model comparison failed to support the notion that disperser behavior lead to different dispersal distances for seeds in fragments vs. continuous forests (Appendix B). We therefore find little support for the hypothesized increases in dispersal limitation following fragmentation, which contrasts sharply with work in other systems documenting limited immigration of seeds into forest fragments (Flinn and Vellend 2005, Cordeiro et al. 2009). Previous research at the study site has demonstrated that, despite having lower population densities in forest fragments (Stouffer et al. 2006), $H$. acuminata's avian frugivores readily move among 


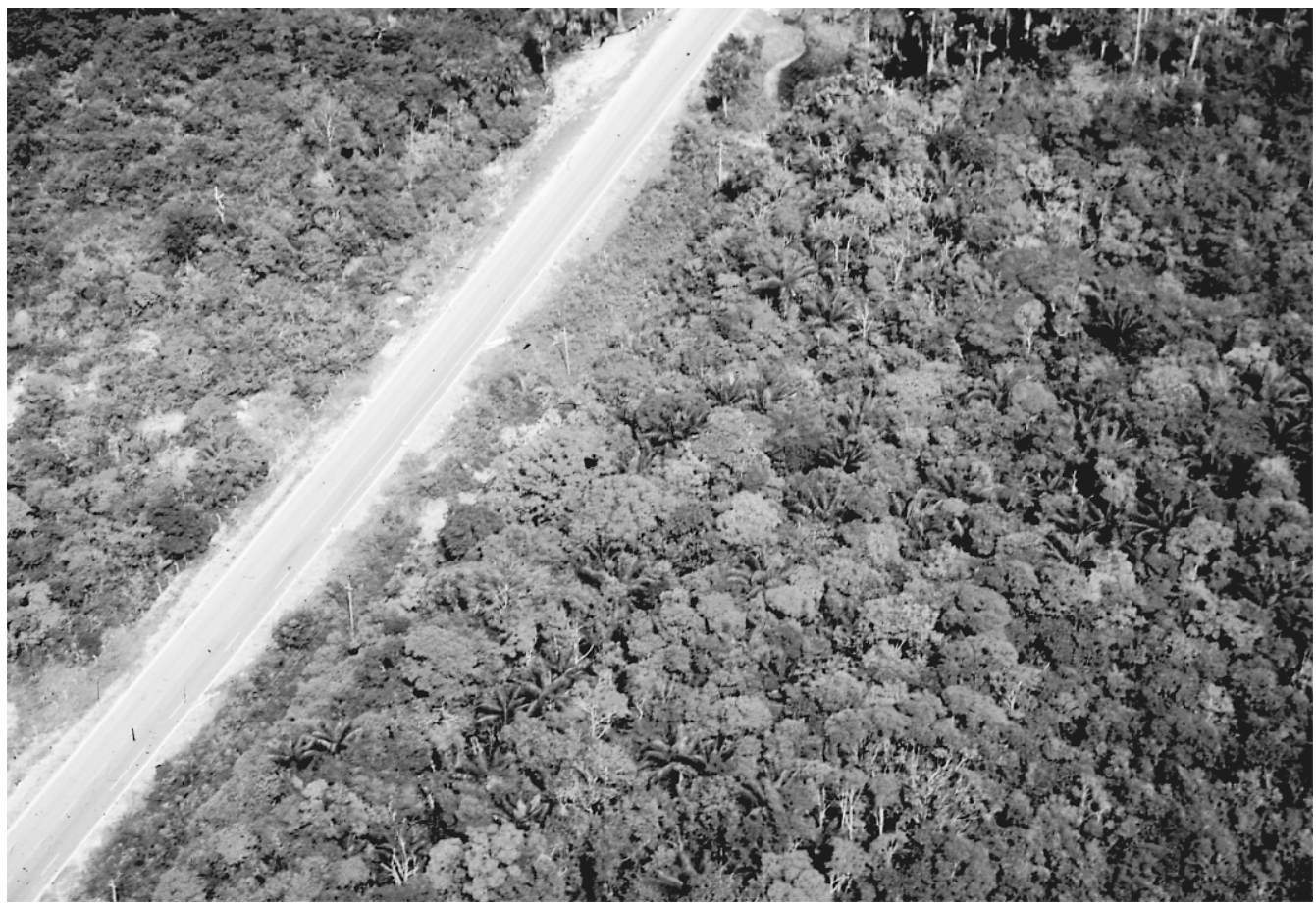

Plate 1. Continuous forest at the Biological Dynamics of Forest Fragments Project (BDFFP), in Brazil, fragmented by the BR-174 highway. Highways are a leading cause of habitat fragmentation in tropical forests. Photo credit: E. M. Bruna.

fragments (M. Anciães, unpublished data). However, species differ considerably in their response to fragmentation and the resulting landscape matrix (Van Houtan et al. 2007). The extent to which seed dispersers, and hence plant seed shadows, are affected by fragmentation depends on dispersers' range sizes, fidelity to natal territory, and physical and behavioral limits (Sodhi et al. 2004).

\section{Effects of abiotic and biotic factors on safe-site limitation}

In contrast to the limited effect of fragmentation on dispersal limitation, our models suggest major effects of fragmentation on the availability of safe sites; safe-site limitation, that is, the percentage of quadrats that failed to receive at least one seed, varied from $45 \%$ to $82 \%$ across study sites. In contrast to previous studies demonstrating the importance of fragmentation on disperser behavior and plant colonization (see review in Flinn and Vellend 2005), biotic factors, specifically negative density-dependent interactions among seedlings and established plants, appeared relatively unimportant. Rather, abiotic factors seem to be the most important control on seedling establishment.

Two abiotic factors appear to exert major and positive influences on seedling establishment. Light availability influenced seedling establishment at two levels. Seedlings failed to establish above threshold values of canopy opening, implying limitation by high light (Fig. 2). Elevated levels of photosynthetically active radiation are associated with higher air temperatures and reduced relative humidity (Kapos et al. 1997; E. M. Bruna, unpublished data), increasing the risk of seed and seedling desiccation or mortality. Below the estimated threshold value, however, seedling establishment increased with light levels (Fig. 3). Slight increases in light availability also led to greater seedling growth and survival in an experimental study with another Amazonian Heliconia species (Schleuning et al. 2009), and similar results have been observed for tropical tree seedlings (Montgomery and Chazdon 2002).

The second abiotic factor, habitat favorability, as reflected in the strong positive effects of established plant density on seedling establishment, may reflect underlying soil quality. Understory herbs tend to have specific microhabitat requirements (Whigham 2004), and in a site near ours, Costa et al. (2005) found strong links between soil structure and herb distribution and abundance. Furthermore, fine-scale spatial variation in soil properties and soil chemistry have previously been shown to influence the probability of seed germination (reviewed in Baskin and Baskin 1998). Studies of tree dynamics at some sites in the BDFFP have uncovered links between tree biomass, soil texture, and nutrient properties (Laurance et al. 1999); however, little is known of how these properties influence seed germination. Experiments manipulating variables that have been shown to be key for germination of plants in other tropical systems (e.g., leaf litter, water availability, 
herbivory) would help in elucidating the importance of these factors of plant recruitment.

Safe-site limitation, specifically, the effect of light on seedling establishment, appears to be the critical driver of differences in population demography of $H$. acuminata between fragments and continuous forests (Fig. 3). To our knowledge no other studies have compared spatial heterogeneity in light availability in fragments and continuous forest, nor how this heterogeneity influences seedling recruitment. One of the most common consequences of fragmentation is reduced seedling establishment, particularly for forest understory species such as $H$. acuminata (e.g., Benitez-Malvido et al. 1999, Bruna 2002). After isolation, increased light levels often lead to seed dessication or high rates of seedling mortality for shade-tolerant species (Bruna 2002). These effects could be manifest either through different thresholds for establishment or different responses to ambient light levels in fragments and forest. Our results suggest that plants in continuous forests respond more strongly to slight increases in light levels (Fig. 3). Understory light levels were greater and more spatially heterogeneous in fragments than in continuous forests, possibly creating an environment in which higher photosynthetic activity is associated with greater evapotranspiration and lower net carbon assimilation (Kitajima 1994). Minimizing water losses rather than maximizing carbon gain may be a more sensible strategy for shade-tolerant species in stressful environments (Walters and Reich 2000).

Two important caveats to our conclusions bear discussion. First, we examined the importance of seed vs. safe-site limitation during one season, uncovering high spatial variation in the importance of these two factors within quadrats in a $0.5-\mathrm{m}$ plot and between plots. A number of studies suggest that temporal variation in the factors that drive recruitment is likely to have important effects on plant population dynamics (Schupp 1990, Connell and Green 2000, Ibáñez et al. 2007), so that the relative importance of safe-site and seed limitation will vary spatially and temporally (Turnbull et al. 2000). For instance, the abundance of disperser, pollinator, and predator populations can all vary from year to year (Pascarella 1998). In addition, interannual differences in climate (e.g., rainfall) may also lead to variation in seed production (Wright 2005) and seedling establishment (Ibáñez et al. 2007), both of which can in turn affect frugivore populations (Wright et al. 1999). Given the importance of light in limiting seedling establishment for $H$. acuminata, a result we believe is potentially indicative of dessication, dry years may drive interannual variation in seedling establishment for this species. Understanding how this variation interacts with the spatial processes that determine plant recruitment, particularly in the context of human habitat modification, is a critical component of biodiversity conservation. The methods presented in this paper can easily incorporate interannual variation in seed production (Eq. 1) or in the processes that drive safe-site limitation (Eqs. 4-6) by estimating separate parameters for each year for which data are available, which we believe is a fruitful avenue for future research. Second, remnant forest patches are rarely protected from hunting, fire, or other forms of human disturbance like those at the BDFFP are, and all of these factors could exacerbate the factors leading to low plant recruitment in fragments and biodiversity loss (Galetti et al. 2009). Our study provides much-needed empirical data on how the strength of both pre-dispersal and postdispersal factors influence recruitment in an Amazonian understory plant, as well as how the pattern of limitation varies spatially. However, we believe it is essential to conduct similar studies in a diversity of fragmented landscapes, as well as with a broader diversity of plant functional groups, to better predict the consequences of fragmentation on plant recruitment (Flinn and Vellend 2005). To date dispersal mechanisms have received the most attention, with studies suggesting less dispersal limitation for wind- and vertebrate-dispersed species (Flinn and Vellend 2005, Muscarella and Fleming 2007, Cordeiro et al. 2009). Furthermore, most of the attention in tropical systems has focused on tree species (e.g., Norden et al. 2009), despite the fact that understory plants represent up to $25 \%$ of the plant diversity in tropical forests (Gentry and Emmons 1987). Future research should move beyond these systems to explore the effectiveness of key traits associated with plant performance and functional strategies in predicting the relative importance of dispersal and safe-site limitation (Grime 1977, Reich et al. 1997, Westoby et al. 2002, Wright et al. 2004). For instance, shade-tolerant species are predominantly dispersed by animals and exhibit a contrasting set of functional traits from the pioneers, such as large seed size, low fecundity, longer life span, high-density wood, low specific leaf area, and low leaf $\mathrm{N}$ content (Wright et al. 2004). These characteristics may lead to greater dispersal limitation and a greater availability of safe sites relative to pioneers. An understanding of the importance of lifehistory traits on seed and safe-site limitation, coupled with adult plant performance data, can be used to evaluate population viability and to identify the demographic transitions most critical to population establishment and growth (Bruna 2003).

\section{ACKNOWLEDGMENTS}

We thank Liza Comita, Kathryn Flinn, and an anonymous reviewer for helpful comments on the manuscript. We also thank the technicians and students who helped conduct the censuses and are grateful for the logistical support of the BDFFP and its staff. Financial support was provided by the U.S. National Science Foundation (award DEB-0614339 to M. Uriarte and DEB-0614149 and INT 98-06351 to E. M. Bruna) and the Institute for Food and Agricultural Sciences, Center for Latin American Studies, and College of Agricultural and Life Sciences at the University of Florida. This is publication number 548 in the BDFFP Technical Series. 


\section{Literature Cited}

Aizen, M. A., and P. Feinsinger. 1994. Forest fragmentation, pollination, and plant reproduction in a chaco dry forest, Argentina. Ecology 75:330-351.

Antongiovanni, M., and J. P. Metzger. 2005. Influence of matrix habitats on the occurrence of insectivorous bird species in Amazonian forest framents. Biological Conservation 122:441-451.

Baskin, C. C., and J. M. Baskin. 1998. Seeds: ecology, biogeography, and evolution of dormancy and germination. Academic Press, New York, New York, USA.

Benitez-Malvido, J., G. Garcia-Guzman, and I. D. KossmannFerraz. 1999. Leaf-fungal incidence and herbivory on tree seedlings in tropical rainforest fragments: an experimental study. Biological Conservation 91:143-150.

Berry, F., and W. J. Kress. 1991. Heliconia: an identification guide. Smithsonian Institution Press, Washington, D.C., USA.

Bierregaard, R. O., C. Gascon, T. E. Lovejoy, and R. Mesquita. 2002. Lessons from Amazonia: the ecology and conservation of a fragmented forest. Yale University Press, New Haven, Connecticut, USA.

Bruna, E. M. 1999. Seed germination in rainforest fragments. Nature 402:139.

Bruna, E. M. 2002. Effects of forest fragmentation on Heliconia acuminata seedling recruitment in central Amazonia. Oecologia 132:235-243.

Bruna, E. M. 2003. Are plants in rain forest fragments recruitment limited? Tests with an Amazonian herb. Ecology 84:932-947.

Bruna, E. M., and W. J. Kress. 2002. Habitat fragmentation and the demographic structure of an Amazonian understory herb Heliconia acuminata. Conservation Biology 16:12561266.

Bruna, E. M., W. J. Kress, O. F. da Silva, and F. Marques. 2004. Heliconia acuminata reproductive success is independent of local flowering plant density. Acta Amazonica 34: 467-471.

Burkey, T. V. 1993. Edge effects in seed and egg predation at two neotropical rainforest sites. Biological Conservation 66: 139-143.

Burnham, K. P., and D. R. Anderson. 2002. Model selection and inference: a practical information-theoretic approach. Springer-Verlag, New York, New York, USA.

Cain, M. L., H. Damman, and A. Muir. 1998. Seed dispersal and the Holocene migration of woodland herbs. Ecological Monographs 68:325-347.

Cardoso da Silva, J. M., and M. Tabarelli. 2000. Tree species impoverishment and the future flora of the Atlantic forest of northeast Brazil. Nature 404:72-74.

Clark, D. B., and D. A. Clark. 1989. The role of physical damage in the seedling mortality regime of a neotropical rain forest. Oikos 55:225-230.

Clark, J. S., E. Macklin, and L. Wood. 1998. Stages and spatial scales of recruitment limitation in southern Appalachian forests. Ecological Monographs 68:213-235.

Clark, J. S., M. Silman, R. Kern, E. Macklin, and J. HilleRisLambers. 1999. Seed dispersal near and far: patterns across temperate and tropical forests. Ecology 80:1475-1494.

Connell, J. H., and P. T. Green. 2000. Seedling dynamics over thirty-two years in a tropical rain forest tree. Ecology 81:568584.

Cordeiro, N. J., H. J. Ndangalasi, J. P. McEntee, and H. Howe. 2009. Disperser limitation and recruitment of an endemic African tree in a fragmented landscape. Ecology 90:10301041.

Costa, F. R. C., W. E. Magnusson, and R. C. Luizao. 2005. Mesoscale distribution patterns of Amazonian understorey herbs in relation to topography, soil and watersheds. Journal of Ecology 93:863-878.
Crawley, M. J. 1990. The population dynamics of plants. Philosophical Transactions of the Royal Society B 330:125140.

de Oliveira, A. A., and S. A. Mori. 1999. A central Amazonian terra firme forest. I. High tree species richness on poor soils. Biodiversity and Conservation 8:1219-1244.

Feinsinger, P., K. G. Murray, S. Kinsman, and W. H. Busby. 1986. Floral neighborhood and pollination success in four hummingbird-pollinated cloud forest plant species. Ecology 67:449-464.

Feinsinger, P., H. Tiebout III, and B. E. Young. 1991. Do tropical bird-pollinated plants exhibit density-dependent interactions? Field experiments. Ecology 72:1953-1963.

Flinn, K. M. 2007. Microsite-limited recruitment controls fern colonization of post-agricultural forests. Ecology 88:31033114.

Flinn, K. M., and M. Vellend. 2005. Recovery of forest plant communities in post-agricultural landscapes. Frontiers in Ecology and the Environment 3:243-250.

Galetti, M., H. C. Giacomini, R. S. Bueno, C. S. S. Bernardo, R. M. Marques, R. S. Bovendorp, C. E. Steffler, P. Rubim, S. K. Gobbo, and C. I. Donatti. 2009. Priority areas for the conservation of Atlantic forest large mammals. Biological Conservation 142:1229-1241.

Gentry, A. H., and L. H. Emmons. 1987. Geographical variation in fertility, phenology and composition of the understory of neotropical forests. Biotropica 19:216-217.

Greene, D. F., and E. A. Johnson. 1992. Can the variation in samara mass and terminal velocity on an individual plant affect the distribution of dispersal distances? American Naturalist 139:825-838.

Grime, J. P. 1977. Evidence for the existence of three primary strategies in plants and its relevance to ecological and evolutionary theory. American Naturalist 111:1169-1194.

Hansen, M. C., S. V. Stehman, P. V. Potapov, T. Loveland, J. R. G. Townshend, R. DeFries, K. W. Pittman, B. Arunarwati, F. Stolle, M. K. Steininger, M. Carroll, and C. DiMiceli. 2008. Humid tropical forest clearing from 2000 to 2005 quantified using multi-temporal and multi-resolution remotely sensed data. Proceedings of the National Academy of Sciences (USA) 105:9439-9444.

Holbrook, K. M., and B. A. Loiselle. 2007. Using toucangenerated seed shadows to estimate seed dispersal in Amazonia Ecuador. Pages 300-321 in A. J. Dennis, E. W. Schupp, R. Green, and D. W. Westcott, editors. Seed dispersal: theory and its applications in a changing world. CABI Publishing, Wallingford, UK.

Horvitz, C. C., and D. W. Schemske. 1994. Effects of dispersers, gaps, and predators on dormancy and seedling emergence in a tropical herb. Ecology 75:1949-1958.

Ibáñez, I., J. S. Clark, S. LaDeau, and J. Hille Ris Lambers. 2007. Exploiting temporal variability to understand tree recruitment response to climate change. Ecological Monographs 77:163-177.

Iverson, L. R., and A. M. Prasad. 1998. Predicting abundance of 80 tree species following climate change in the eastern United States. Ecological Monographs 68:465-485.

Jacquemyn, H., and R. Brys. 2008. Effects of stand age on the demography of a temperate forest herb in post-agricultural forests. Ecology 89:3480-3489.

Jonckheere, I., K. Nackaerts, B. Muys, and P. Coppin. 2005. Assessment of automatic gap fraction estimation of forests from digital hemispherical photography. Agricultural and Forest Meteorology 132:96-114.

Kapos, V., E. Wandelli, J. L. Camargo, and G. Ganade. 1997. Edge-related changes in environment and plant responses due to forest fragmentation in Central Amazonia. Pages 33-44 in W. F. Laurance and R. O. Bierregaard, Jr., editors. Tropical forest remnants: ecology, management, and conservation of fragmented communities. University of Chicago Press, Chicago, Illinois, USA. 
Kitajima, K. 1994. Relative importance of photosynthetic traits and allocation patterns as correlates of seedling shade tolerance of 13 tropical trees. Oecologia 98:419-428.

Kobe, R. K., and C. F. Vriesendorp. 2009. Size of sampling unit strongly influences detection of seedling limitation in a wet tropical forest. Ecology Letters 12:220-228.

Laurance, W. F., P. M. Fearnside, S. Laurance, P. Delamonica, T. E. Lovejoy, J. M. Rankin-de Merona, J. Q. Chambers, and C. Gascon. 1999. Relationship between soils and Amazon forest biomass: a landscape-scale study. Forest Ecology and Management 118:127-138.

Levine, J. M., and D. J. Murrell. 2003. The community-level consequences of seed dispersal patterns. Annual Review of Ecology, Evolution and Systematics 34:549-574.

Melo, F. P. L., D. Lemire, and M. Tabarelli. 2007. Extirpation of large-seeded seedlings from the edge of a large Brazilian Atlantic forest fragment. Ecoscience 14:124-129.

Montgomery, R. A., and R. L. Chazdon. 2002. Light gradient partitioning by tropical tree seedlings in the absence of canopy gaps. Oecologia 131:165-174.

Muller-Landau, H. C., S. J. Wright, O. Calderón, S. P. Hubbell, and R. B. Foster. 2002. Assessing recruitment limitation: concepts, methods and examples for tropical forest trees. Pages 35-53 in J. Levey, W. R. Silva, and M. Galetti, editors. Seed dispersal and frugivory: ecology, evolution and conservation. CAB International, Oxfordshire, UK.

Muscarella, R., and T. H. Fleming. 2007. The role of frugivorous bats in tropical forest succession. Biological Reviews 82:573-590.

Norden, N., R. L. Chazdon, A. Chao, Y.-H. Jiang, and B. Vilchez-Alvarado. 2009. Resilience of tropical rain forests: tree community reassembly in secondary forests. Ecology Letters 12:385-394.

Pascarella, J. B. 1998. Hurricane disturbance, plant-animal interactions, and the reproductive success of a tropical shrub. Biotropica 30:416-424.

R Development Core Team. 2008. R: a language and environment for statistical computing. R Development Core Team, Vienna, Austria.

Reich, P. B., M. B. Walters, and D. S. Ellsworth. 1997. From tropics to tundra: global convergence in plant functioning. Proceedings of the National Academy of Sciences (USA) 94: 13730-13734.

Ribbens, E., J. A. Silander, Jr., and S. W. Pacala. 1994. Seedling recruitment in forests: calibrating models to predict patterns of tree seedling dispersion. Ecology 75:1794-1806.

Russo, S. E., S. Portnoy, and C. K. Augspurger. 2006 Incorporating animal behavior into seed dispersal models: implications for seed shadows. Ecology 87:3160-3174.

Schleuning, M., V. Huaman, and D. Matthies. 2009. Experimental assessment of factors limiting seedling recruitment of an Amazonian understory herb. Biotropica 41:57-65.

Schnurr, J. L., C. D. Canham, R. S. Ostfeld, and J. Inouye. 2004. Neighborhood analyses of small-mammal dynamics: impacts on seed predation and seedling establishment. Ecology 85:741-755.

Schupp, E. W. 1990. Annual variation in seedfall, postdispersal predation, and recruitment in a neotropical tree. Ecology 71: 504-515.
Sizer, N., and E. V. J. Tanner. 1999. Responses of woody plant seedlings to edge formation in a lowland tropical rainforest, Amazonia. Biological Conservation 91:135-142.

Sodhi, N. S., L. H. Liow, and F. A. Bazzaz. 2004. Avian extinctions from tropical and subtropical forests. Annual Review of Ecology, Evolution and Systematics 35:323-345.

Stiles, F. G. 1979. Annual cycle in co-adapted community of hummingbird and flowers in a very humid tropical forest of Costa Rica. Revista De Biología Tropical 271:75-101.

Stouffer, P. C., R. O. Bierregaard, C. Strong, and T. E. Lovejoy. 2006. Long-term landscape change and bird abundance in Amazonian rainforest fragments. Conservation Biology 20:1212-1223.

Svenning, J. C., and F. Skov. 2002. Mesoscale distribution of understorey plants in temperate forest: the importance of environment and dispersal. Plant Ecology 160:169-185.

Svenning, J. C., and S. J. Wright. 2005. Seed limitation in a Panamanian forest. Journal of Ecology 93:853-862.

Terborgh, J., L. Lopez, V. P. Nuñez, M. Rao, G. Shahabuddin, G. Orihuela, M. Riveros, R. Ascanio, G. H. Adler, T. D. Lambert, and L. Balbas. 2001. Ecological meltdown in predator-free forest fragments. Science 294:1923-1926.

Turnbull, L. A., M. J. Crawley, and M. Rees. 2000. Are plant populations seed-limited? A review of seed sowing experiments. Oikos 88:225-238.

Van Houtan, K. S., S. L. Pimm, J. L. Halley, R. O. Bierregaard, and T. E. Lovejoy. 2007. Dispersal of Amazonian birds in continuous and fragmented forest. Ecology Letters 103:219229 .

Walters, M. B., and P. B. Reich. 2000. Tradeoffs in low-light $\mathrm{CO}_{2}$ exchange: a component of variation in shade tolerance among cold-temperate tree seedlings. Functional Ecology 14: $155-165$.

Wenny, D. G. 2000. Seed dispersal, seed predation, and seedling recruitment of a neotropical montane tree. Ecological Monographs 70:331-351.

Westcott, D. A., and D. L. Graham. 2000. Patterns of movement and seed dispersal of a tropical frugivore. Oecologia 122:249-257.

Westoby, M., D. S. Falster, A. T. Moles, P. A. Vesk, and I. J. Wright. 2002. Plant ecological strategies: some leading dimensions of variation between species. Annual Review of Ecology and Systematics 33:125-159.

Whigham, D. E. 2004. Ecology of woodland herbs in temperate deciduous forests. Annual Review of Ecology Evolution and Systematics 35:583-621.

Wright, I. J., et al. 2004. The worldwide leaf economics spectrum. Nature 428:821-827.

Wright, S. J. 2002. Plant diversity in tropical forests: a review of mechanisms of species coexistence. Oecologia 130:1-14.

Wright, S. J. 2005. The El Niño Southern Oscillation influences tree performance in tropical rainforests. Pages 295-310 in E. Bermingham, C. W. Dick, and C. Moritz, editors. Tropical rainforests: Past, present, and future. University of Chicago Press, Chicago, Illinois, USA.

Wright, S. J., C. Carrasco, O. Calderon, and S. Pato. 1999. The El Niño Southern Oscillation variable fruit production, and famine in a tropical forest. Ecology 80:1632-1647.

Zar, J. H. 1996. Biostatistical analysis. Third edition. Prentice Hall, Upper Saddle River, New Jersey, USA.

\section{APPENDIX A}

Corrected Akaike information criterion $\left(\mathrm{AIC}_{\mathrm{c}}\right)$ for models used to analyze seedling abundance as a result of seed and safe-site limitation (Ecological Archives E091-091-A1).

\section{APPENDIX B}

Corrected Akaike information criterion $\left(\mathrm{AIC}_{\mathrm{c}}\right)$ for models used to analyze effects of fragmentation on seedling establishment (Ecological Archives E0-91-091-A2). 